\title{
Investigation of the potential carcinogenicity of a range of chromium containing materials on rat lung
}

\author{
L S LEVY, ${ }^{1}$ P A MARTIN, ${ }^{1}$ AND P L BIDSTRUP ${ }^{2}$ \\ From the Institute of Occupational Health, ${ }^{1}$ University of Birmingham, Birmingham B15 2TT, and 11 Sloane \\ Terrace Mansions, ${ }^{2}$ Sloane Terrace, London SW1, UK
}

ABSTRACT Twenty one chromium containing materials were examined for carcinogenic activity in a two year study using an intrabronchial pellet implantation system whereby pellets loaded with test material were surgically implanted into the lower left bronchus of rats. The principal aim of the study was to extend our knowledge of the carcinogenic potential of chromium compounds and, in particular, chromates $\left(\mathrm{Cr}^{6+}\right)$. A statistically significant incidence of treatment related lung tumours was found with some sparingly soluble chromate materials. All tumours were large keratinising squamous carcinomas of the left lung, except for a single left lung adenocarcinoma and two left lung anaplastic carcinomas. No bronchial carcinomas $(0 / 100)$ were seen in the negative control group (blank pellet loaded with cholesterol), whereas bronchial carcinomas (22/48 and 25/100) occurred in the two positive control groups which received pellets loaded with 20 -methylcholanthrene and calcium chromate respectively. Among the 20 test materials, only three groups gave statistically significant numbers of bronchial carcinomas. Two of these were groups receiving different samples of strontium chromate which gave 43/99 and 62/99 tumours. The third group, zinc chromate (low solubility), gave $5 / 100$ bronchial carcinomas. A further zinc chromate group (Norge composition) produced $3 / 100$ bronchial carcinomas which was not statistically significant. A few lung tumours were observed in other test groups.

The toxicological effects of exposure to chromium containing materials have been known since the early nineteenth century. Their irritant and corrosive action on the skin and nasal mucosa have been widely reported, and in the United Kingdom notification of cases of chrome ulceration to HM Chief Inspector of Factories has been a statutory obligation since 1919. The first reported case of cancer associated with chromates was in $1890^{1}$ and was that of an adenocarcinoma of the nasal turbinates in a chrome pigment worker from Scotland.

Early observations of lung cancer in German workers in the bichromate producing industry were made in 1911 and 1912 but not published until 1932. ${ }^{2}$ Later observations were made in the German industry throughout the $1930 \mathrm{~s}^{3}$ but only since the late 1940s have epidemiological surveys conducted in the United States of America, the United Kingdom, and elsewhere attempted to quantify the risk. ${ }^{4-8}$

These studies showed that an increased risk of lung cancer existed for workers engaged in manufacturing

Accepted 5 August 1985 bichromates $\left(\mathrm{Cr}^{6+}\right)$ from the ore, chromite $\left(\mathrm{Cr}^{3+}\right)$. The industrial production of bichromates potentially exposes the process workers to chrome ore, calcium chromate, sodium and potassium chromate, and dichromate and chromic acid as well as other intermediate materials. In the mid 1970s the risk of bronchial carcinoma was shown to occur also among chrome pigment makers. ${ }^{9-11}$ The chrome pigments include materials used to impart colour, mainly greens, yellows, and oranges, from a variety of lead chromate containing pigments, with additives to produce the various shades required, as well as zinc chromate containing pigments. A second major use of a particular group of chromate pigments is in coatings designed to prevent the corrosion of metals. This group includes zinc and strontium chromates. In other groups of workers exposed to chromium containing materials - for instance, chrome platers, ${ }^{12-15}$ chromate spray painters, ${ }^{1617}$ and stainless-steel welders $^{18}$-reports are sparse and inconclusive. The most recent evaluation of the carcinogenic risk of chromium and its compounds by the International Agency for Research on Cancer (IARC) in $1982^{19}$ is: 
“A Evidence for carcinogenicity to humans (sufficient) An increased incidence of lung cancer has been observed among workers in the chromate producing industry and possibly also among chromium platers and chromium alloy workers. There is a suggestion that cancers at other sites are also increased in such populations. The chromium compound(s) responsible has not been specified.

\section{B Evidence for carcinogenicity to animals (sufficient) Calcium chromate is carcinogenic to rats after its administration by several routes, including intrabronchial implantation. Chromium chromate, strontium chromate, and zinc chromate produce local sarcomas in rats at the sites of their application. Inad- equate evidence was available for the carcinogenicity in mice and rats of barium chromate, lead chromate, chromic acetate, sodium dichromate, and chromium carbonyl."}

These conclusions are based on IARC's interpretation of the experimental and epidemiological evidence then available. Later studies ${ }^{2021}$ and data presented in the present paper indicate that a more precise evaluation of carcinogenic potential may now be possible.

To identify the $\mathrm{Cr}^{6+}$ compound(s) that may have caused the increased risk of lung cancer in the manufacture of bichromates and chrome pigments, animal models have been used with a wide variety of routes of application but few directly to the lung itself. A more specific animal experiment was a study in which a series of chromium containing materials encountered in the bichromate producing industry were tested, using the rodent lung intrabronchial pellet implantation technique. ${ }^{22}$ Both calcium chromate and zinc potassium chromate (a chrome pigment not occurring in the industry but included to test a solubility theory) induced lung tumours $(8 / 100$ and $3 / 100$ respectively). Both results were statistically significant $(\mathrm{p}<0.05)$.

The present study was undertaken to complement these earlier findings using the same experimental technique but applied to 20 chromium containing compounds including seven from the bichromate producing industry and 13 made and used in the chrome pigment industry. The nature of the materials tested is such that the results may well be relevant to other chromium using industries including chromium plating and spray painting.

\section{Materials and methods}

The technique used in the present study was modified from that originally developed and described by Kuschner $e t$ al and referred to as the "intrabronchial pellet implantation procedure" in which a metal wire $\frac{\bar{\alpha}}{\overline{0}}$ basket or pellet containing the test material is sur-? gically implanted into the left bronchus of an an- $\vec{F}$ aesthetised rat. ${ }^{23}$ The metal mesh acts as a framework $\stackrel{\text { ? }}{+}$ in and around which the test material, mixed with? cholesterol, is suspended and from which it leaches. This enables a selected zone of bronchial epithelium 5 to be exposed to a putative carcinogen for a con- $\triangle$ tinuing period. The animals were studied for two years, after which time the survivors were killed and $\vec{A}$ the lungs and other organs presenting abnormalities. at necropsy were examined microscopically. The pro- $\vec{\omega}$ cedure for coating the pellets was modified from that $\stackrel{\circ}{\circ}$ used previously since the stability of the chrome pigments might be altered when heated for a period in 3 excess of two minutes. Test material $(10 \mathrm{~g})$ was added $\omega$ to cholesterol $(10 \mathrm{~g})$ and placed in a glass bottle. Afterthorough mixing, aliquots $(0.5 \mathrm{~g})$ were taken and heated to $160^{\circ} \mathrm{C}$ to give a molten mixture into which ${ }^{\omega}$ the preweighed pellet was dipped. Each pellet was $\bigcirc$ held by the hooks, suspended into the molten material for ten seconds, taken out, and allowed to solidify. Ino this way five pellets were coated in the two minute heating period allowed for each aliquot. Excess ma- $\overrightarrow{0}$ terial was removed from the body of the pellet byo fitting it into an implantation trochar. The coated pellet was then reweighed and the exact weight of test material in and around each pellet calculated. All pellets were kept in individual bijou bottles and sterilised before surgical implantation into the left bronchus. $\frac{\mathrm{D}}{\mathrm{Q}}$ Equal numbers of male and female random bred eight $\stackrel{2}{\rightarrow}$ to ten week old Porton-Wistar rats (100 per group) $\overrightarrow{\overrightarrow{0}}$ obtained from A Tuck \& Sons Ltd, Rayleigh, Essex, were used in all experiments. Autoclaved cubed diet (rat and mouse breeding diet, Pilsburys) and drinking. water were available ad libitum.

Table 1 lists the test materials which were provided 3 by the bichromate producing and chrome pigment industries. The study was conducted in accordance with.the guidelines published by the Food and Drug Ad-O응 ministration (FDA) in a document entitled "Non- $₹$ clinical laboratory studies-proposed regulations for윽 good laboratory practice" (1976).

The pathological evaluation of the bronchial changes evoked by this technique were broadlyñ classified as inflammatory, preneoplastic, and neoplastic. Independent re-evaluation of suspect neo- $N$ plastic lung lesions and a selection of normal lungs was performed by an external pathologist.

In the case of lung tumour data the statisticalo analysis was similar to a previous study and was based on the "null hypothesis" that none of the test $\stackrel{?}{+}$ substances is carcinogenic. ${ }^{22}$ Each animal will there- 0 fore have had the same probability of developing ao bronchial carcinoma regardless of the chemical on

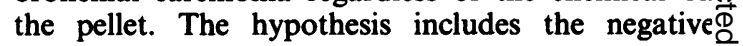


Table 1 Characterisation of chromium containing materials

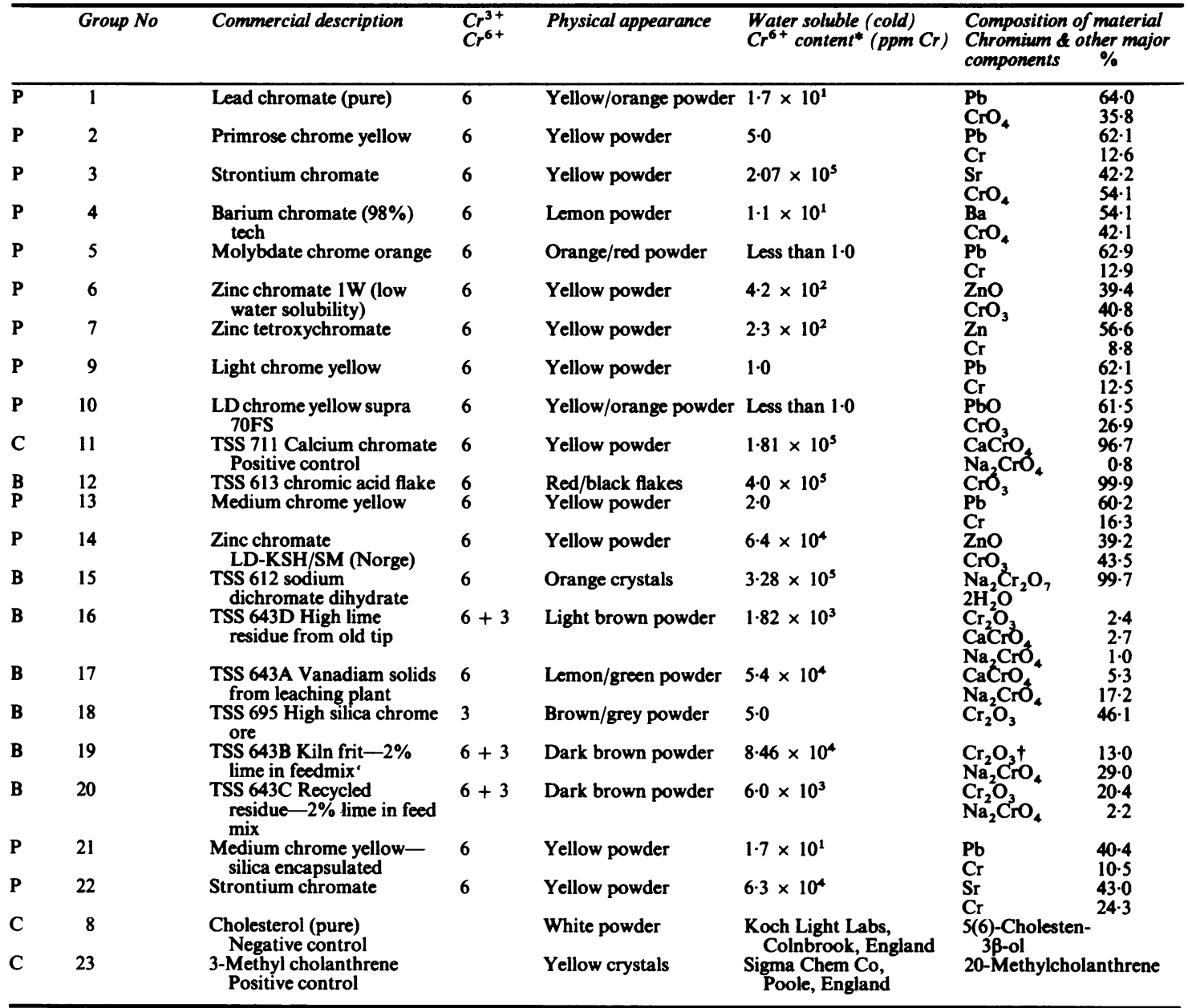

*Method used was: British Standards Institution BS3483: Part C2: 1980 for testing pigments for paints. Determination of matter soluble in water (cold extraction method); in conjunction with International Standard ISO 3856/5-1980(E). Appendix D. Part 5: Determination of hexavalent chromium content of the pigment and extender portion of the paint-diphenylcarbazide spectrophotometric method.

$\mathbf{P}=$ Materials encountered in the chrome pigment industry.

B = Materials encountered in the bichromates producing industry.

$\mathrm{C}=$ Control materials.

†This material contained $0.7 \% \mathrm{CaO}$ which is equivalent to $1.95 \% \mathrm{CaCrO}_{4}$. In practice most of the calcium would be present as the chromate.

control group 8 but not the positive control groups (group 11, calcium chromate and group 23, 20methylcholanthrene). The rationale behind the null hypothesis is based on the assumption that the occurrence of a primary bronchial carcinoma is rare. The evaluation of the bronchial carcinoma data assumes a Poisson distribution for the occurrence of lung cancer in rats, and our experience of zero tumours in over 500 control animals receiving blank pellets loaded with cholesterol supports this assumption. Thus an "expected" incidence of lung tumour per group (E) may be calculated from the number of observed bron- chial carcinomas $(\mathrm{O})$ that are found in the total number (test groups plus negative control group) of rats. The calculation of probability is similar to that used in a previous study ${ }^{22}$ and is in accordance with the general principals set out in the IARC monograph on screening assays for carcinogens. ${ }^{24}$

Results

GENERAL OBSER VATIONS

The animals remained in good general health during the two year period of the experiment with $95.7 \%$ 
alive at $\mathbf{4 0 0}$ days and an overall survival at $\mathbf{7 0 0}$ days of $53.9 \%$.

Student's $t$ test was performed on the weight data for each treatment group and compared with the negative control group (group 8); there was no significant increase or decrease in body weight in test groups.

Lung tumours first appeared in the positive control $\stackrel{\infty}{\circ}$ groups (group 23-20 methylcholanthrene) on day $294 \stackrel{\Rightarrow}{\Rightarrow}$ (male rat) and group 11 (calcium chromate) on day 439 (male rat). In groups 3 and 22 (both strontium? chromate) the first lung tumour appeared in group 3 음

Table 2 Summary of all lung findings after macroscopic and microscopic examination

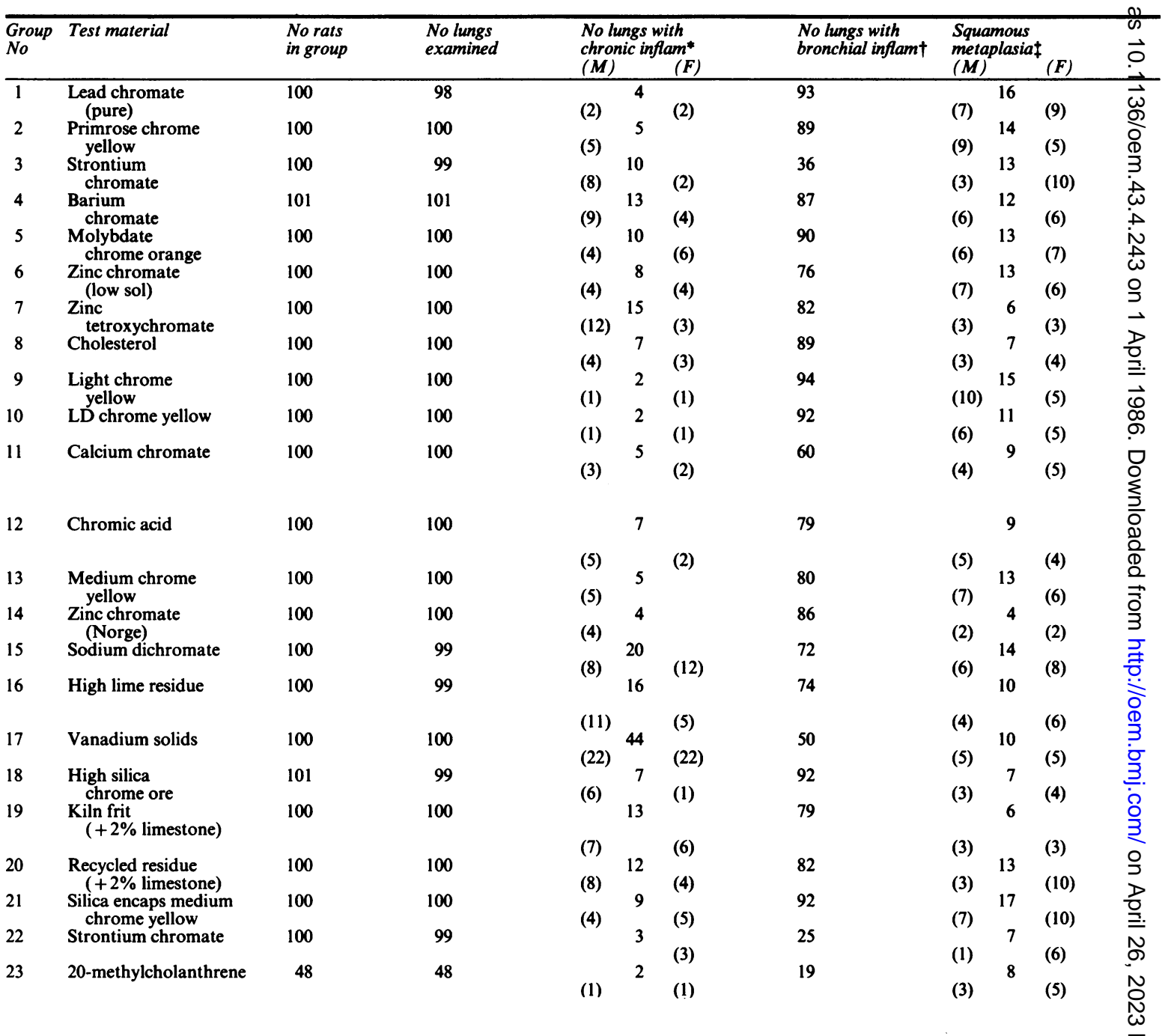

*Chronic inflammation includes all changes of an inflammatory nature, either of micro/macroscopic description. Lung tumours with such changes arre excluded.

+Bronchial inflammation is scored where this is the major inflammatory response. It varied from very slight to severe epithelial changes (microscop $\ddagger$ This condition was scored for all lungs exhibiting squamous metaplasia except those with squamous carcinoma. 
on day 340 (female rat) and in group 22 on day 291 (male rat). Thereafter lung tumours continued to appear until the end of the study, with 18/172 appearing only at the terminal kill ( 2 years), whereas the remainder $(154 / 172)$ were considered to be the direct cause of death of the animals in which they occurred.
PATHOLOGY OF LUNG LESIONS

The relevant findings from the macroscopic and microscopic examinations of the lungs are summarised in table 2. As expected, there were various tissue responses to the implanted pellets and test materials but these fell well into the pathological catego-

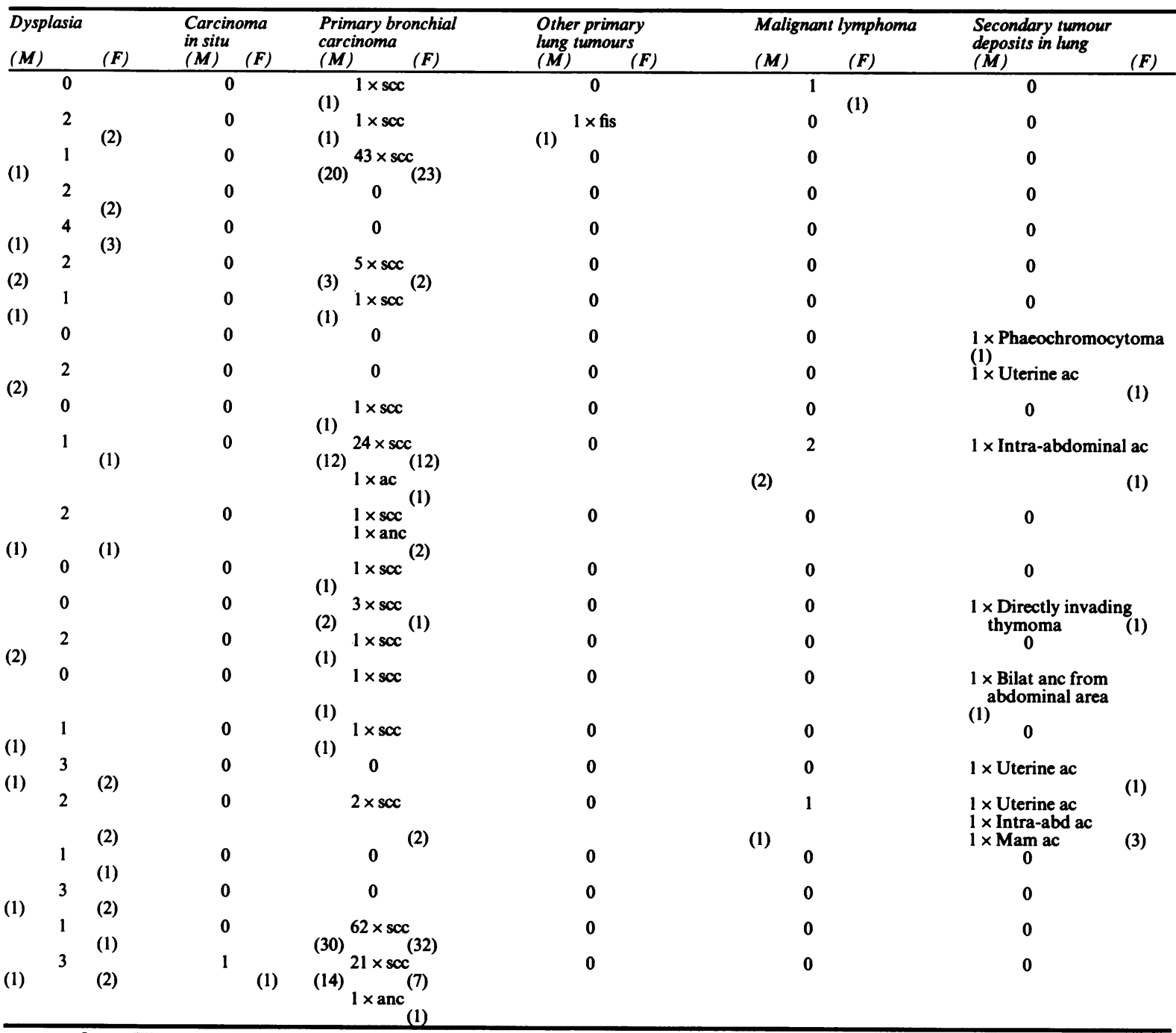

fis = Fibrosarcoma.

soc = Squamous carcinoma.

ac $=$ Adenocarcinoma.

anc $=$ Anaplastic carcinoma .

mam ac $=$ Mammary adenocarcinoma.

uter ac = Uterine adenocarcinoma.

intra abd ac $=$ Intra-abdominal adenocarcinoma.

bilat anc $=$ Bilateral anaplastic carcinoma from abdominal area. 
ries described in the table. Particular care was taken to distinguish between inflammatory, preneoplastic, and neoplastic response. The left lung bronchial carcinomas recorded in this table tended to affect a major part of the left lung. Inflammatory and metaplastic changes of the lung and bronchus (figs 1-3) did not appear to show any treatment relationship apart from a high incidence of chronic parenchymal inflammatory changes in group 17 (vanadium solids), presumably related to the presence of calcium vanadate $\left(\mathrm{Ca}_{3}\left(\mathrm{VO}_{4}\right)_{2}\right)$ which may hydrolyse to produce vanadium pentoxide, a well known lung irritant.

\section{PRIMARY BRONCHIAL CARCINOMAS}

These lesions were invariably keratinising squamous carcinomas (figs 4 and 5) of the left lung with varying degrees of necrosis. Occasionally metastases to the kidney or hilar lymph nodes were seen, as was invasion of the right lung or diaphragm. One adenocarcinoma was observed (fig 6) in group 11, calcium chromate, and two lesions were diagnosed as anaplastic carcinomas (fig 7), one in group 12, chromic acid and one in group 23, 20-methylcholanthrene.

In this study the "induction period" was used to denote the time in days from the surgical insertion of the pellet to the observation of a lung tumour at postmortem examination. Table 3 gives a summary of the bronchial carcinoma data. This shows clearly the differing carcinogenic potential of the various chromium containing $\left(\mathrm{Cr}^{6+}\right)$ materials tested by this system.

\section{Discussion}

LUNG TUMOURS AND EXPERIMENTAL TREATMENT Our experience of the technique, and that of Laskin et $a l^{25}$ shows that three basic criteria must be met to establish a causal link between the development of lung tumours and treatment. These are: (1) that the neoplasm should be a bronchial carcinoma (squamous carcinoma, adenocarcinoma, or anaplastic carcinoma); (2) the tumour should originate in the left lung; and (3) that it should occur in the latter part (after 250 days) of the animal's life. All lung tumours in table 3 satisfied these criteria and are thus considered to be related to treatment.

\section{INTER PRETATION OF LUNG TUMOUR DATA}

In a previous study (table 4) it was shown that in a series of 14 chromium containing materials only three

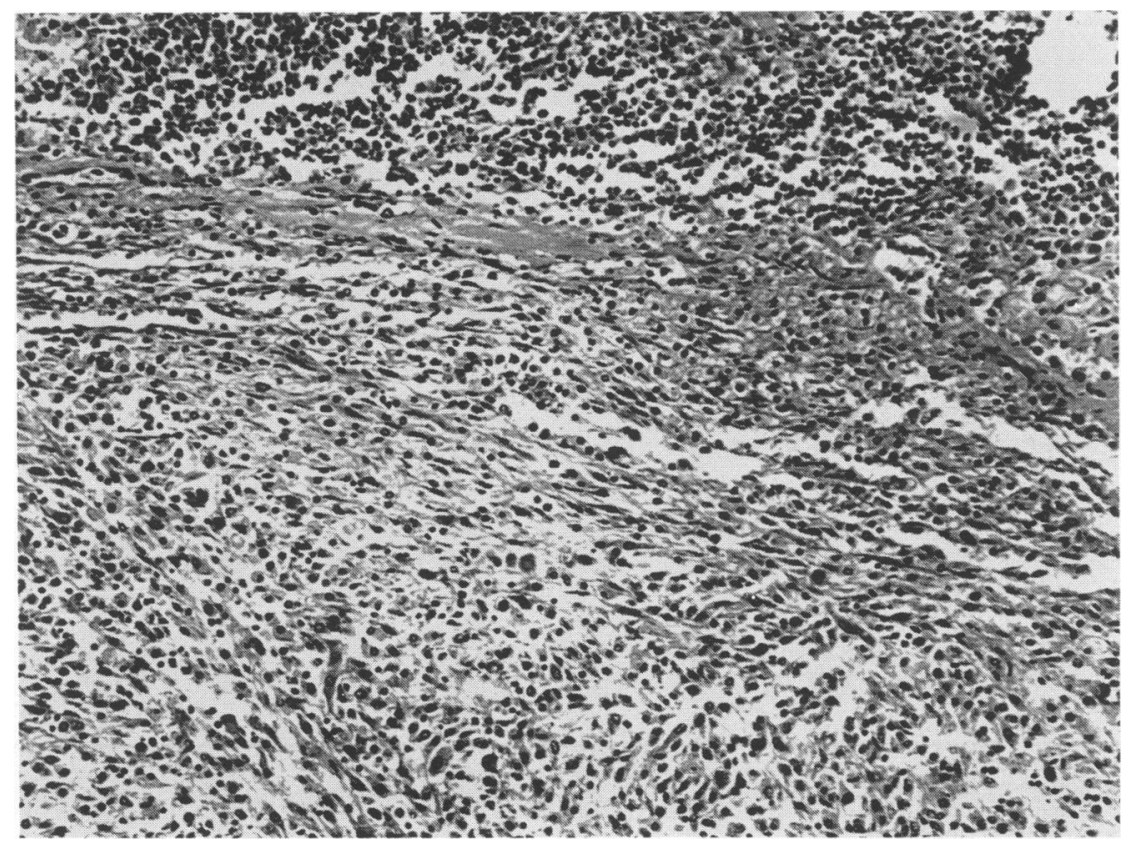

Fig 1 Section from edge of an abscess with necrotic debris surrounded by inflamed granulation tissue. Some fibroblasts are pleomorphic. Fibroblastic responses in such lesions are often intense and zones of well formed metaplastic bone are not uncommon. Another feature is regenerative proliferation of bronchiolar epithelium which may simulate invasive carcinoma.

$(H \& E \times 130$.) 


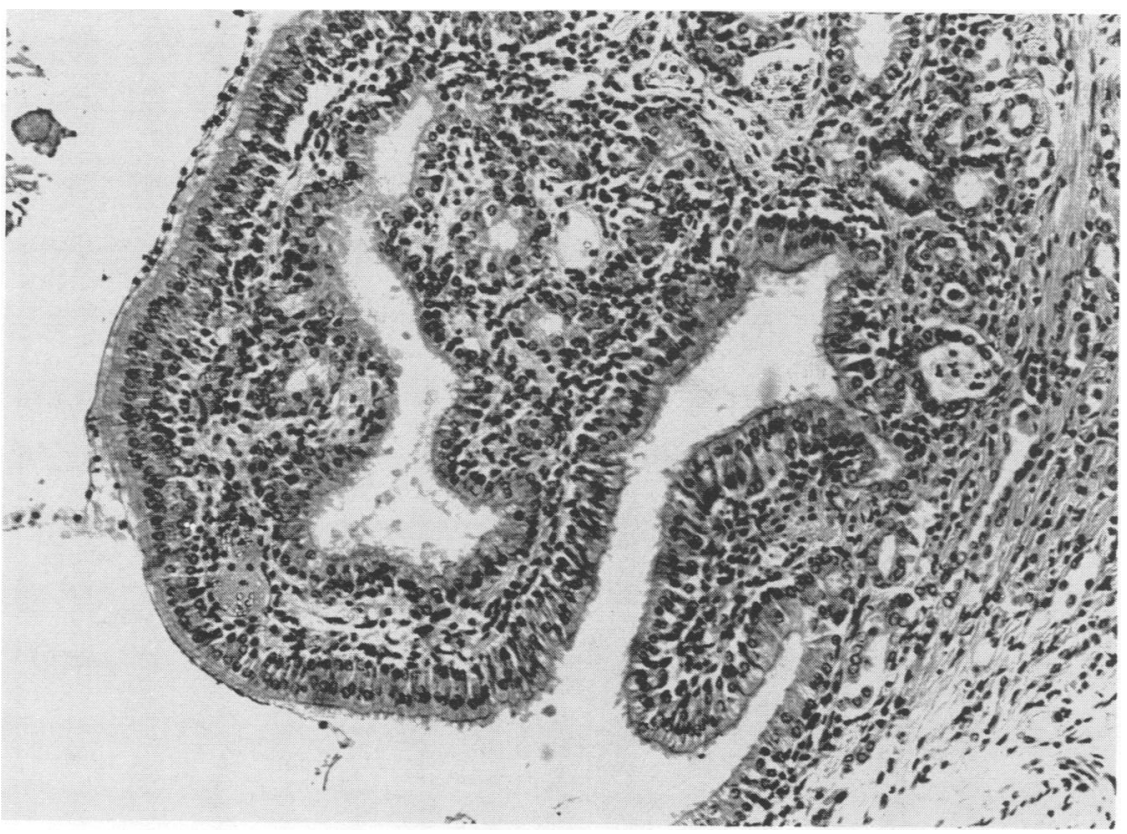

Fig 2 Example of mild bronchial inflammation. Mucosa is thickened with polypoid folds and lining ciliated columnar epithelium is slightly hyperplastic. Mixed inflammatory cells are present in submucosa, extending to about depth of submucous glands. ( $H \& E \times 130$.)

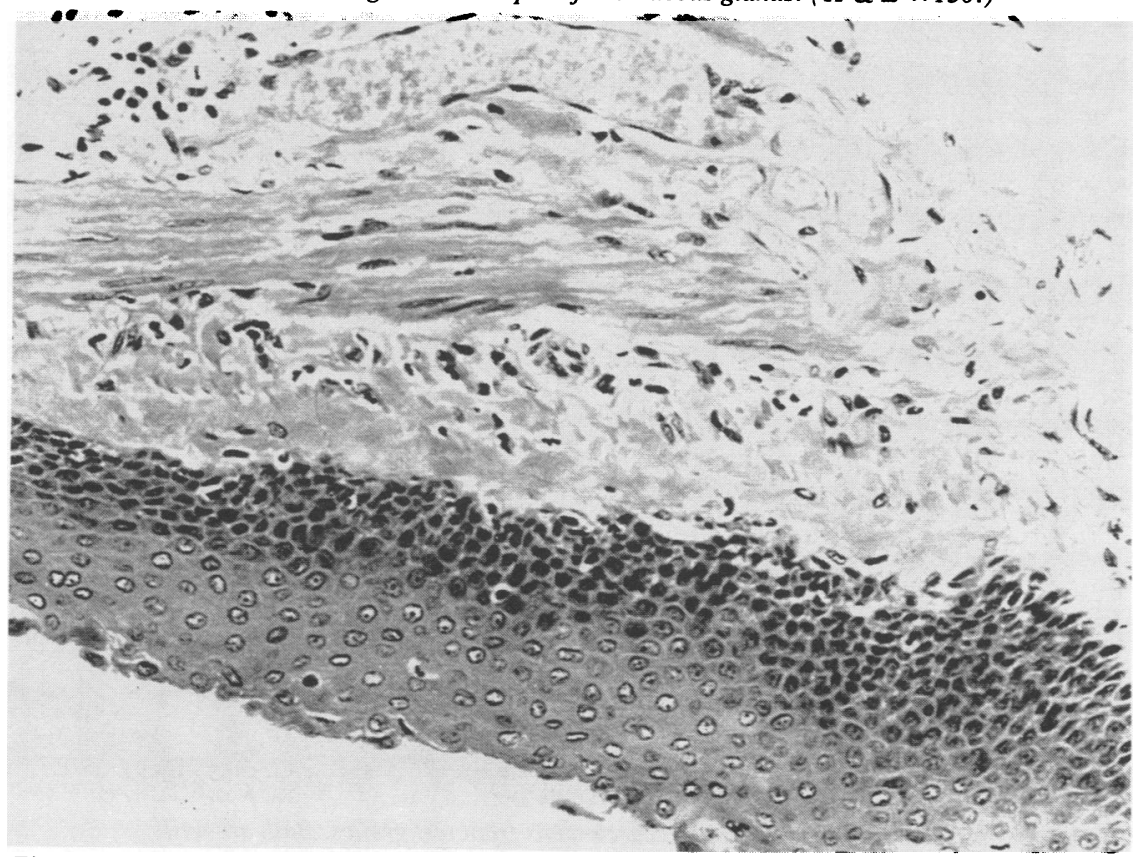

Fig 3 A focus of squamous metaplasia which has completely replaced normal ciliated columnar epithelium. Cells are stratified and appear to be maturing from basal layer outwards as in normal squamous epithelium - for example, in oesophagus or cervix uteri. No keratin layer is seen here but some foci of squamous metaplasia are heavily keratinised. Mitotic figures, seen at higher power, are few and morphologically normal. ( $H \& E \times 210$.) 

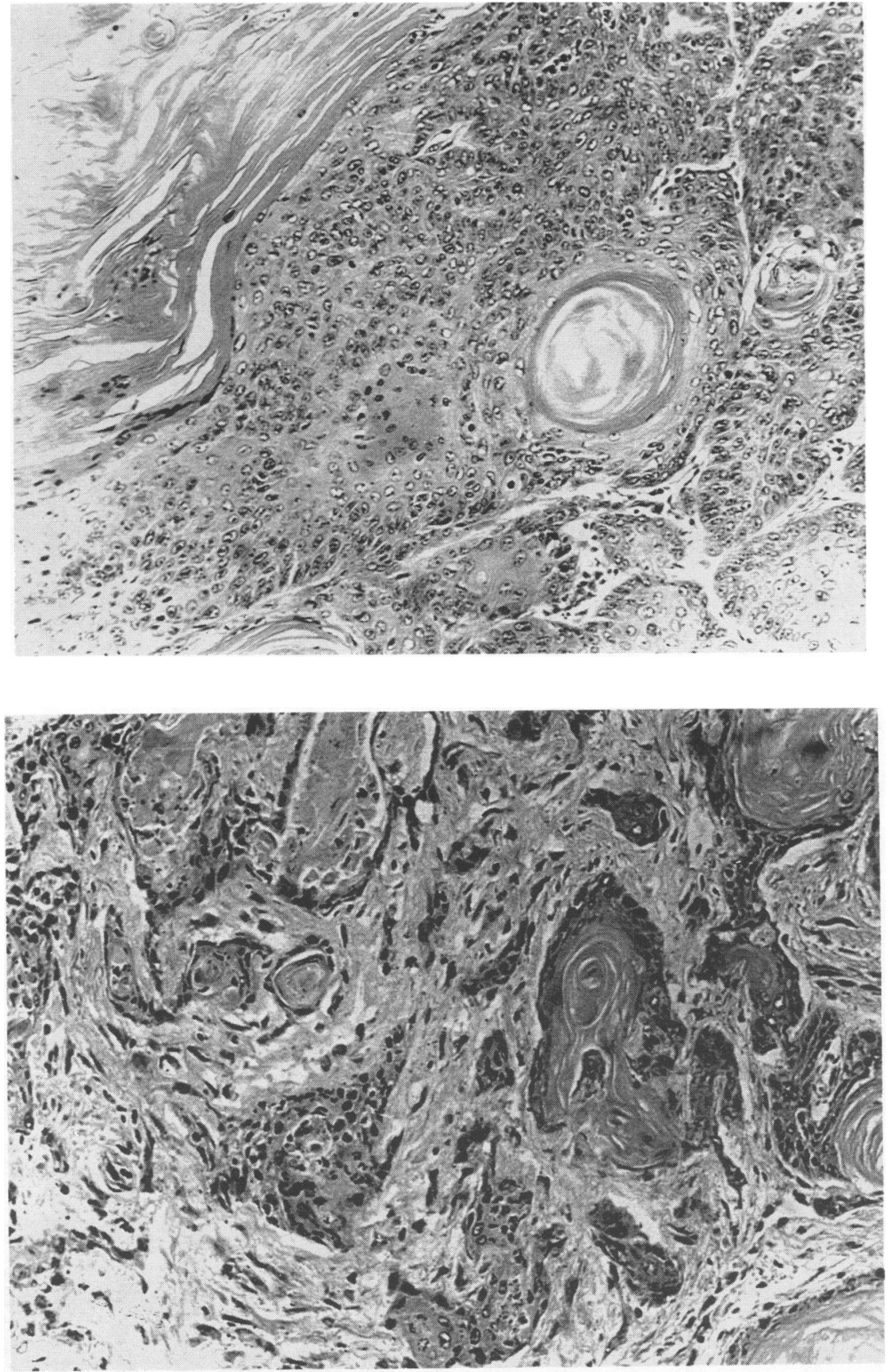

Figs 4 and 5 Two bronchial squamous carcinomas from test groups. Both are well differentiated, keratinising lesions. Tumour shown in fig 5 has a rather more dispersed, infiltrated growth pattern. No distinctive morphological features were identified in squamous carcinomas from any of the test groups or from two positive control groups. Both tumours illustrated here are histologically identical to squamous carcinomas of bronchus in man. (Both $H \& E \times 130$ and $\times 210$.) 


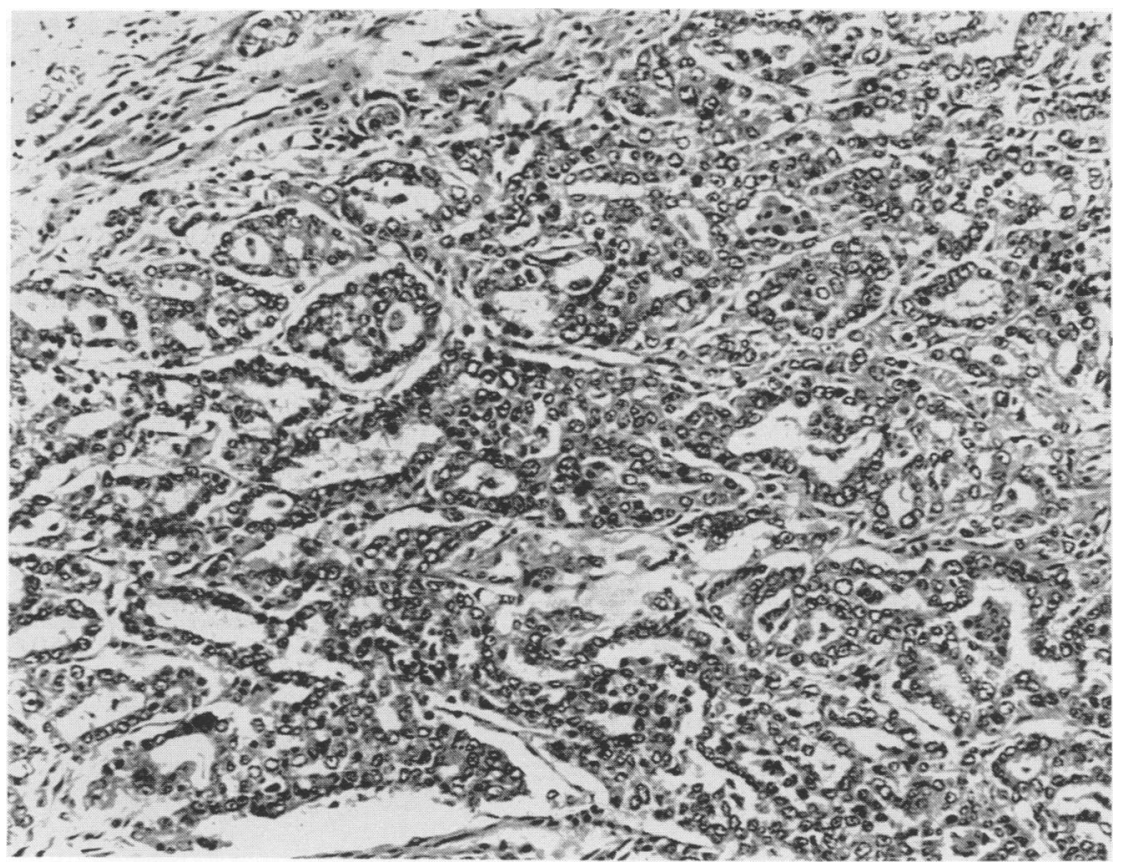

Fig 6 Primary adenocarcinoma of bronchus, showing clear acinar growth pattern. This is a rare tumour in rats. Histologically it is similar to adenocarcinoma of lung in man where such tumours have certain distinctive clinical features: a greater incidence among women than men, a tendency to develop in peripheral parts of bronchial tree, and a weak association with inhaled carcinogens (except perhaps asbestos). ( $H \& E \times 130$.)

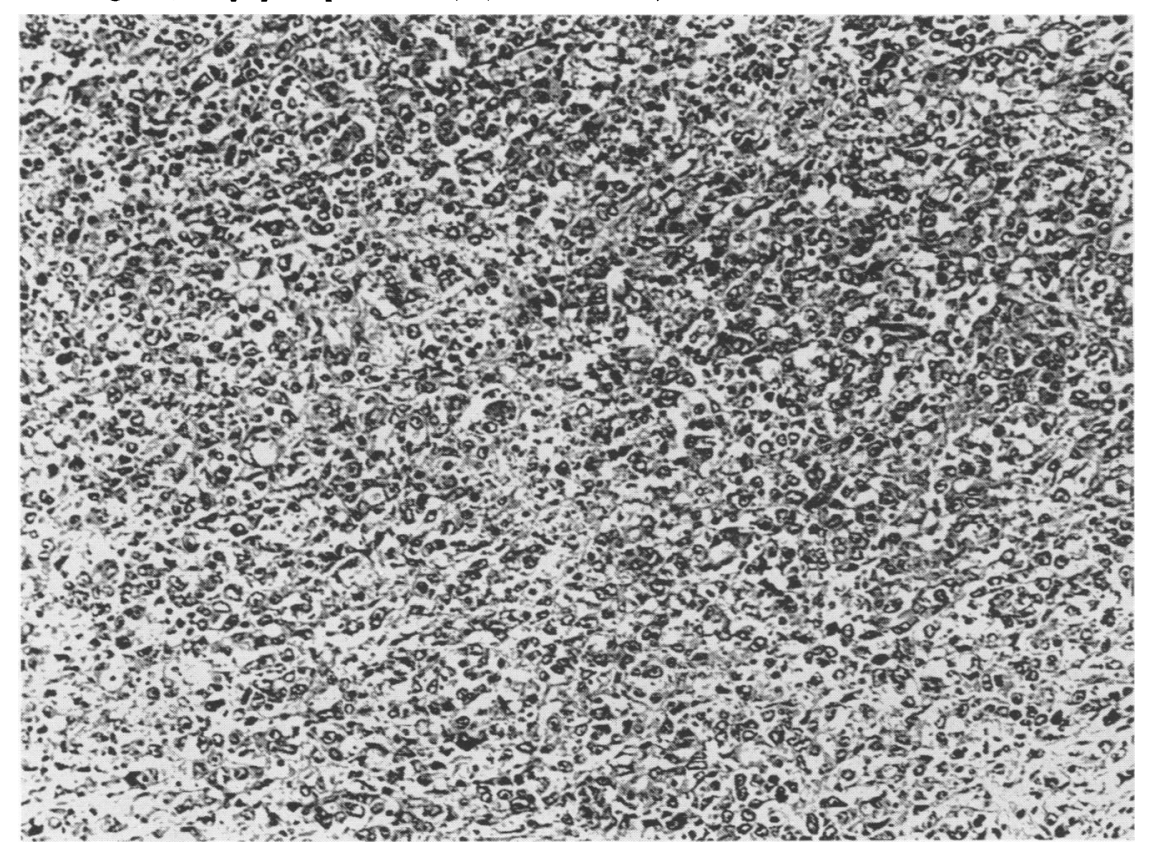

Fig 7 A primary anaplastic carcinoma of bronchus. It may be classified as a small cell lesion (cf WHO scheme) but histological appearances do not resemble an oat cell carcinoma, the commonest form of small cell anaplastic carcinoma in man. Anaplastic tumours are rare in rats and, of the three main tumour types, they have least resemblance to their human counterparts. ( $H \& E \times 130$.) 
produced bronchial carcinomas. These three materials were hexavalent chromates. Only two gave statistically significant numbers of tumours, however, and these (calcium chromate and zinc potassium chromate) may be described as sparingly soluble. A single tumour was also produced with chromic acid.

In the present study, which has included a wider range of hexavalent chromium containing materials, it is convenient to discuss the results as follows (for an overall comparison see table 3 ).

\section{Strontium chromates}

The high incidence of bronchial carcinomas (43/100-group 3 and 62/100-group 22$)$ seen in rats treated with strontium chromate is so obvious that $\frac{3}{2}$ statistical tests for significance are not needed to con- 웅 clude that this material is a strong carcinogen under $\Rightarrow$ these study conditions. The reason for the difference $\stackrel{S}{\rightarrow}$ in tumour incidence between the two strontium chro- $\bar{C}$ mate groups may be due to differences in the composition of the pigment (crystal structure and particle size, for example, since the materials came from sepa- $\mathbb{Q}$ rate suppliers) or it may be a function of the inherent variability of the experimental method. The only other reported studies with strontium chromate are those of Hueper in which he produced 17/28 intra- $\overrightarrow{ }$ thoracic tumours (type unstated) after intrapleural injection and 15/33 local intramuscular sarcomas after implantation. ${ }^{26}$

Table 3 Summary of bronchial carcinoma data

\begin{tabular}{|c|c|c|c|c|c|c|c|c|}
\hline $\begin{array}{l}\text { Group } \\
\text { No }\end{array}$ & Test material & $\begin{array}{l}\text { No lungs } \\
\text { examined }\end{array}$ & $\begin{array}{l}\text { No bronchia } \\
\text { carcinomas } \\
(M)\end{array}$ & (F) & Probability* & Significance & \multicolumn{2}{|c|}{$\begin{array}{l}\text { Mean induction period } \\
(+/-S D) \text { in days }\end{array}$} \\
\hline 1 & $\begin{array}{l}\text { Lead chromate } \\
\text { (pure) }\end{array}$ & 98 & (1) & & $0 \cdot 37$ & NS & 502 & \\
\hline 2 & $\begin{array}{l}\text { Primrose chrome } \\
\text { yellow }\end{array}$ & 100 & (1) 1 & & $0 \cdot 37$ & NS & 673 & \\
\hline 3 & $\begin{array}{l}\text { Strontium } \\
\text { chromate }\end{array}$ & 99 & (20) 43 & (23) & - & - & $567 \cdot 3$ & $(119 \cdot 4)$ \\
\hline $\begin{array}{l}4 \\
5\end{array}$ & $\begin{array}{l}\text { Barium chromate } \\
\text { Molybdate }\end{array}$ & $\begin{array}{l}101 \\
100\end{array}$ & $\begin{array}{l}0 \\
0\end{array}$ & & - & - & - & \\
\hline 6 & $\begin{array}{l}\text { Zinc chromate } \\
\text { (low sol) }\end{array}$ & 100 & (3) & (2) & 0.004 & $\mathbf{S}$ & $599 \cdot 8$ & (115) \\
\hline 7 & $\begin{array}{l}\text { Zinc } \\
\text { tetroxychromate }\end{array}$ & 100 & (1) & & $0 \cdot 37$ & NS & 623 & \\
\hline 8 & Cholesterol & 100 & 0 & & - & - & - & \\
\hline 9 & Light chrome yellow & 100 & 0 & & - & $\overline{1}$ & - & \\
\hline 11 & Calcium chromate & 100 & (12) & (13) & - & - & $576 \cdot 4$ & $(98 \cdot 8)$ \\
\hline 12 & Chromic acid & 100 & 2 & (2) & $0 \cdot 19$ & NS & 580 & $(77 \cdot 8)$ \\
\hline 13 & $\begin{array}{l}\text { Medium chrome } \\
\text { yellow }\end{array}$ & 100 & (1) & & $0 \cdot 37$ & NS & 591 & \\
\hline 14 & $\begin{array}{l}\text { Zinc chromate } \\
\text { (Norge) }\end{array}$ & 100 & (2) & (1) & 0.068 & NS & 606 & $(173)$ \\
\hline 15 & Sodium dichromate & 99 & (1) 1 & & $0 \cdot 37$ & NS & 658 & \\
\hline 16 & High lime residue & 99 & (1) & & 0.37 & NS & 726 & \\
\hline 17 & Vanadium solids & 100 & (1) & & $0 \cdot 37$ & NS & 645 & \\
\hline 18 & $\begin{array}{l}\text { High silica } \\
\text { chrome ore }\end{array}$ & 99 & 0 & & - & - & - & \\
\hline 19 & $\begin{array}{l}\text { Kiln frit } \\
\text { (2\% limestone) }\end{array}$ & 100 & 2 & (2) & $0 \cdot 19$ & NS & $573 \cdot 5$ & $(47 \cdot 5)$ \\
\hline 22 & Strontium chromate & 99 & 62 & (32) & - & - & $542 \cdot 5$ & $(116 \cdot 3)$ \\
\hline 23 & 20-Methylcholanthrene & 48 & (14) 22 & (8) & - & - & $575 \cdot 2$ & (134) \\
\hline
\end{tabular}

Number of animals per group was 100 except in groups 4 and 18 which had 101 and group 23 which had 48.

$\mathrm{S}=$ Statistically significant at the $5 \%$ level.

NS $=$ Not statistically significant at the $5 \%$ level.

* $=$ The probability of observed numbers of tumours in each test group may be calculated from the following formula:

$$
\begin{aligned}
P=\frac{e^{-x} \cdot x^{r}}{r} \text { where } r & =\text { number of tumours in test group } \\
x & =\text { mean number of tumours per group. }
\end{aligned}
$$


Table 4 Lung tumours found and microscopically confirmed in first bichromate industry series

\begin{tabular}{|c|c|c|c|c|c|}
\hline Group No & Test material & No rats in group & $\begin{array}{l}\text { Bronchial carcinoma } \\
\text { of left lung }\end{array}$ & $\begin{array}{l}\text { Induction period in } \\
\text { days (range) }\end{array}$ & $\begin{array}{l}\text { Lung tumours not associated } \\
\text { with treatment }\end{array}$ \\
\hline $\begin{array}{l}1 \\
2 \\
3\end{array}$ & $\begin{array}{l}\text { Ground chromate ore } \\
\text { Bolton high lime residue } \\
\text { Residue after alumina } \\
\text { precipitation }\end{array}$ & $\begin{array}{l}100 \\
100 \\
100\end{array}$ & $\begin{array}{l}0 \\
0 \\
0\end{array}$ & & \\
\hline 4 & $\begin{array}{l}\text { Residue from slurry tank- } \\
\text { free of soluble } \mathrm{Cr}\end{array}$ & 100 & 0 & & \\
\hline 5 & Residue from vanadium filter & 100 & 0 & & Pulmonary adenoma of left \\
\hline 6 & Residue from slurry disposal tank & 101 & $\mathbf{0}$ & & $\begin{array}{l}\text { Anaplastic carcinoma of upper } \\
\text { left lung }\end{array}$ \\
\hline $\begin{array}{l}7 \\
8 \\
9 \\
10 \\
11 \\
12 \\
13 \\
14 \\
15 \\
16 \\
17 \\
18 \\
19 \\
20\end{array}$ & $\begin{array}{l}\text { Sodium dichromate dihydrate } \\
\text { Sodium chromate } \\
\text { Chromic acid (ground) } \\
\text { Chromic acid (metal) } \\
\text { Calcium chromate } \\
\text { Chromic chloride hexahydrate } \\
\text { Zinc chromate-type II* } \\
\text { Chrome tan } \\
\text { Pellet + cholesterol } \\
\text { Blank pellet } \\
100 \% \text { 3-MCA } \\
50 \% \text { 3-MCA } \\
25 \% \text { 3-MCA } \\
100 \% \text { 3-MCA }\end{array}$ & $\begin{array}{r}100 \\
100 \\
100 \\
100 \\
100 \\
100 \\
100 \\
100 \\
150 \\
150 \\
48 \\
48 \\
48 \\
48\end{array}$ & $\begin{array}{l}0 \\
0 \\
1 \\
0 \\
8 \dagger \\
0 \\
3 \dagger \\
0 \\
0 \\
0 \\
36 \\
18 \\
13 \\
34\end{array}$ & $\begin{array}{l}560 \\
604(473-734) \\
708(657-734)\end{array}$ & $\begin{array}{l}\text { Lymphoma of right lung } \\
\text { Adenoma of right lung } \\
\text { Adenocarcinoma of right lung }\end{array}$ \\
\hline
\end{tabular}

*Zinc potassium chromate.

tStatistically significant at the $5 \%$ level.

$\mathrm{MCA}=20$-methylcholanthrene.

\section{Zinc chromates}

Although bronchial carcinomas were seen in all three groups of chromates containing zinc, only in group 6 (zinc chromate-low solubility) was the number $(5 / 100)$ statistically significant. In group 14 (zinc chromate-Norge), which is of similar composition to group 6, the production of three bronchial carcinomas was not significant ( $p=0.068)$.

Previous studies performed using chromates of zinc need some care in interpretation since the identity of the zinc material used is uncertain. ${ }^{26} 27$ Hueper's work in 1961 states that "zinc yellow" induced both injection site sarcoma and intrapleural tumours. Later reports, however, quote this same study as using zinc chromate hydroxide ${ }^{28}$ or zinc yellow. ${ }^{29}$ In this latter reference a footnote is added to the effect that "it is not certain whether the zinc yellow used in these studies was zinc chromate, zinc potassium chromate, or zinc yellow (a pigment based on zinc potassium chromate with a formula which approximates to $\left.4 \mathrm{ZnO} \cdot \mathrm{K}_{2} \mathrm{O} \cdot 4 \mathrm{CrO}_{3} \cdot 3 \mathrm{H}_{2} \mathrm{O}\right)$." A previous study by Levy using the zinc potassium chromate (zinc chromate-type II- $\mathrm{K}_{2} \mathrm{CrO}_{4} \cdot 3 \mathrm{ZnCrO} \cdot \mathrm{Zn}(\mathrm{OH})_{2}$ of 99-100\% purity) gave $3 / 100$ bronchial carcinomas (all squamous) ${ }^{22}$; and this result was statistically significant (table 4).

The single tumour recorded in group 7 (zinc tetroxychromate) is not easy to explain. Table 1 shows that there is a relatively low amount of chromium $(8 \cdot 8 \%)$ in this form of zinc chromate and this may in part account for its lack of activity.

\section{Lead chromates}

Within the seven lead chromate containing groups four were squamous carcinomas, one in each of groups 1, 2, 10, and 13 (table 3). These results are not statistically significant. Nevertheless, because of the rarity of this lesion in control rats it is important to consider their relevance. In previous studies with lead chromate pigments the precise form of lead chromate, which can vary considerably, has not always been stated, and intramuscular or subcutaneous injections have always been used. ${ }^{26} 30-32$ Some of these studies have produced a high incidence of sarcomas at the site of injection ${ }^{3132}$ : the significance of this finding is uncertain.

It is thought that the present study more accurately represents the potential of lead chromate containing materials as possible lung carcinogens, and that lead chromate is non-carcinogenic or has an extremely low carcinogenic potential under the conditions used.

\section{Barium chromate}

No bronchial carcinomas were produced by this material in the present study. Hueper subjected rats to intramuscular or intrapleural implants of barium chromate; no tumours were observed in the intramuscular study and only one in the intrapleural study. ${ }^{26}$ Although the animal data are limited, there is no evidence from this or other studies to suggest that barium chromate is carcinogenic. 
Highly soluble chromates

Chromic acid produced two bronchial carcinomas (one squamous and one anaplastic carcinoma) and each was responsible for the death of the male rat in which it occurred. Previous studies by Laskin et al and Levy using the intrabronchial pellet technique produced $0 / 100$ and $1 / 100$ squamous carcinomas respectively with chromic acid. ${ }^{22} 26$ The IARC considered the animal data insufficient for evaluation, ${ }^{29}$ and from the result of the present study it may be concluded that chromic acid may, at most, evoke a weak carcinogenic response under the conditions of the bioassay.

Sodium dichromate tested by intramuscular or intrapleural injection, ${ }^{33}$ or both, or intramuscular implantation ${ }^{26}$ did not produce tumours in rats. The present result and that of an earlier intrabronchial pellet implantation study ${ }^{22}$ suggests that sodium dichromate is not carcinogenic, or at most is an extremely weak carcinogen.

\section{Bichromate: production process materials}

Chemically, these materials are not closely related, but as they may be present at some stage in the process of bichromates production they are conveniently discussed together.

Studies using trivalent chrome ore have produced no evidence of carcinogenicity, even by the subcutaneous route, and it is thus concluded that the negative result for chrome ore (group 18 table 3) represents a true non-carcinogenic response in animal systems. In a previous study a material described as Bolton high lime residue did not produce any bronchial carcinomas. ${ }^{22}$ Laskin et al, however, using the same technique induced a single squamous carcinoma in 100 treated rats, with a material described as "process residue." 25 It is of interest to note that group 16 material contained $2.7 \% \mathrm{CaCrO}_{4}$, the Bolton high lime residue contained $2.4 \% \mathrm{CaCrO}_{4}$, and the process residue used by Laskin et $a^{25}$ contained up to $3 \%$ $\mathrm{CaCrO}_{4}$. It is concluded that a weak carcinogenic response, at most, may be represented by the single tumour seen in this and in the Laskin study and that it is most probably due to the $\mathrm{CaCrO}_{4}$ content. The single bronchial carcinoma seen in group 17 (vanadium solids) and the two squamous carcinomas produced by group 19 (kiln frit-2\% limestone in feedmix), represent a weak carcinogenic response due to the presence of calcium chromate. Group 20 (recycled residue- $2 \%$ limestone in feedmix) gave no bronchial carcinomas and because the material contains only a small fraction of hexavalent chromium (see table 1) it is concluded that this is a true negative result.
CHROMATE CARCINOGENESIS AND INDUSTRIAL

IMPLICATIONS

The main reason for the toxicological distinction between hexavalent and trivalent chromium is that $\stackrel{\oplus}{+}$ hexavalent chromium (as the chromate ion) is readily transported into the cell ${ }^{34-37}$ whereas trivalent chromium appears unable to cross cell membranes. ${ }^{38} 39$ Once inside the cell, the chromate ion is enzymatically reduced to the biologically active trivalent form and it is $\mathrm{Cr}^{3+}$ which is able to form ligands with macromolecules, including DNA. ${ }^{40}$ Reduction of $\mathrm{Cr}^{6+}$ to $\mathrm{Cr}^{3+}$ must occur close to the cellular DNA to allow formation of potentially damaging chromium complexes with critical DNA targets. If this reduction occurs in the extracellular fluids then the chromium will be unavailable for reaction with other molecules. This $\vec{\omega}$ is consistent with the findings that trivalent chromium it compounds have been found to be non-carcinogenic iv in animal studies, whereas certain hexavalent chro- $\omega$ mium materials are carcinogenic. It is believed, how- 을 ever, that many of the reported animal studies have not distinguished between the carcinogenic potential $\frac{7}{0}$ of hexavalent chromium containing materials with sufficient precision for useful advice to be given on the $\vec{\bullet}$ use and handling of chromates in the industrial con- $\infty$ text. As an example, the ready production of injection site sarcomas by single or repeated injections has not been particularly helpful in the interpretation of epidemiological data.

The model used in this and a previous study is aimed directly at the target tissue for man, the bronchial epithelium. The loaded implanted pellet as well as releasing the chromate ion presents a constant irritant stimulus (often thought a potentiator for neoplastic development). Factors that will determine the response of the rat lung will be the amount of chromate ion contained in a pellet, the rate of release of chromate ion to the target tissue, and the lipid/water interactions and lipoprotein penetration at the cell wall interface.

The lung tumour results show some interesting trends, particularly in relation to solubility, and if one considers principally the pure chromium compounds then it is apparent that neither the highly soluble (chromic acid or sodium dichromate) nor the insoluble (lead chromate pigments and barium chromate) can be considered to be overtly carcinogenic in the system. Only those chromates described as "sparingly" or of "medium" solubility (strontium, calcium, and zinc chromate) gave a frankly neoplastic response and the epidemiological evidence confirms this result. In the case of the bichromate production process materials the data are more difficult to interpret, but the limited conclusion that may be drawn is that if any of the process materials are carcinogenic under the conditions of this bioassay system it is probably those 
containing calcium chromate.

The results of this study of bichromate production materials, taken together with those of a previous study, ${ }^{22}$ suggest that the introduction of the "no lime" process, with the consequent reduction in risk of calcium chromate exposure for bichromate workers, may partly explain the reduction in the risk of lung cancer seen in the industry. ${ }^{41}$ Improved industrial hygiene must also be considered a contributory factor.

The findings for chromate pigments (lead and zinc chromates) and those of previous animal studies, may help to explain the reported lung cancer risk for chromate pigment workers. The workers in this industry tend to have a mixed exposure to both lead and zinc chromate, but the evidence of both animal and human studies strongly support the hypothesis that this risk may be entirely due to exposure to zinc chromates. This is confirmed by the epidemiological findings of Davies, who was able to show that workers did not experience an increased risk of lung cancer when exposed to lead chromate alone, even under conditions capable of evoking overt lead poisoning. ${ }^{2042}$

The experimental model used here seems to yield results that are corroborated by epidemiological findings among groups of workers exposed to chromium containing materials and thus the results may be of value in estimating human risk.

We thank Ms Hilary Cross for preparing the histopathological material and also Dr R L Carter, consultant pathologist of the Royal Marsden Hospital, for his help in the pathological evaluation. We gratefully acknowledge the financial support of British Chrome and Chemicals in this and previous studies, the European Pigment Manufacturers Association, Dry Color Manufacturers Association (USA), and the CibaGeigy Corporation throughout this present study.

\section{References}

${ }^{1}$ Newman DA. A case of adenocarcinoma of the left inferior turbinated body, and perforation of the nasal septum in the person of a worker in chrome pigments. Glasgow Medical Journal 1890;33:469.

${ }^{2}$ Lehmann KB. 1st Grun zu einer besonderen Beunruhigung wegan des Auftretans con Lungenkrebs bei Chromatarbeitern vorhanden? Zentralblatt für Gewerbehygiene 1932;19:168-70.

${ }^{3}$ Gross E, Kolsch F. Lung cancer in the chromate dye industry. Archiv für Gewerbepathologie und Gewerbehygiene 1943;12: 164-70.

${ }^{4}$ Machle W, Gregorius F. Cancer of the respiratory system in the United States chromate-producing industry. Public Health Reports 1948;63:1114-27.

${ }^{5}$ Baetjer AM. Pulmonary carcinoma in chromate workers. 1. A review of the literature and reports of cases. Archives of Industrial Hygiene 1950;2:487-516.
${ }^{6}$ Mancuso RF, Heuper WC. Occupational cancer and other health hazards in a chromate plant. A medical appraisal. 1. Lung cancer in chromate workers. Industrial Medicine and Surgery 1951;20:358-63.

${ }^{7}$ US Public Health Service. Health of workers in chromate producing industry. Washington: US Government Printing Office, 1953. (Publication No 920.)

${ }^{8}$ Bidstrup PL, Case RAM. Carcinoma of the lung in workmen in the bichromates-producing industry in Great Britain. $\mathrm{Br} \mathrm{J}$ Ind Med 1956;13:260-4.

${ }^{9}$ Langard S, Norseth T. A cohort study of bronchial carcinomas in workers producing chromate pigments. Br J Ind Med 1975; 32:62-5.

${ }^{10}$ Davies JM. Lung cancer mortality of workers making chrome pigments. Lancet 1978;i:384.

${ }^{11}$ Langard S, Vigander T. Occurrence of lung cancer in workers producing chromium pigments. $\mathrm{Br} J$ Ind Med 1983;40:71-4.

12 Waterhouse JAH. Proceedings: cancer among chromium platers. Br J Cancer 1975;32:262.

${ }^{13}$ Blair A. Mortality among workers in the metal polishing and plating industry, 1915-59. J Occup Med 1980;22:158-62.

${ }^{14}$ Royle H. Toxicity of chromic acid in the chromium plating industry (1). Environ Res 1975;10:39-53.

${ }^{15}$ Royle H. Toxicity of chromic acid in the chromium plating industry (2). Environ Res 1975;10:141-63.

${ }^{16}$ Dalager NA, Mason TJ, Fraumeni JF, Hoover R, Payne WW. Cancer mortality among workers exposed to zinc chromate paints. J Occup Med 1980;22:25-9.

${ }^{17}$ Chiazze L Jr, Ference LD, Wolf PH. Mortality among automobile assembly workers. 1. Spray painters. J Occup Med 1980;22: $520-6$.

${ }^{18}$ Sjogren B. A retrospective cohort study of mortality among stainless steel welders. Scand J Work Environ Health 1980;6:197-200.

${ }^{19}$ International Agency for Research on Cancer. Monographs on the evaluation of carcinogenic risk of chemicals to man. Supp 4. Chemicals, industrial processes and industries associated with cancer in humans. Vols 1 to 29. Lyon: IARC, 1982:91-3.

${ }^{20}$ Davies JM. Lung cancer mortality in workers making lead chromate and zinc chromate at three English factories. $\mathrm{Br} \mathrm{J}$ Ind Med 1984;41:158-69.

${ }^{21}$ Frentzel-Beyme $R$. Lung cancer mortality of workers employed in chromate pigment factories. A multicentric European epidemiological study. J Cancer Res Clin Oncol 1983;105:183-8.

${ }^{22}$ Levy LS. Effects of various chromium-containing materials on rat lung epithelium. London: University of London, 1975. (PhD thesis.)

${ }^{23}$ Kuschner M, Laskin S, Cristofano E, Nelson N. Experimental carcinoma of the lung. Proceedings of the 3rd National Cancer Conference. Philadelphia: Am Cancer Soc Inc, JB Lippincott Company, 1957:485-95.

${ }^{24}$ International Agency for Research on Cancer. Monographs on the evaluation of carcinogenic risk of chemicals to humans. Long-term and short-term screening assays for carcinogens. A critical appraisal. Suppl 2. Lyon: IARC, 1980.

${ }^{25}$ Laskin S, Kuschner M, Drew RT. Studies in pulmonary carcinogenesis. In: Hanna MG Jr, Nettesheim P, Gilbert JR, eds. Inhalation carcinogenesis. Gatlinburg, Tennessee: US Atomic Energy Commission, Division of Technical Information Extension, 1970:321-51.

${ }^{26}$ Hueper WC. Environmental carcinogenesis and cancers. Cancer Res 1961;21:842-57.

${ }^{27}$ Steffee CH, Baetjer AM. Histopathologic effects of chromate chemicals. Arch Environ Health 1965;11:66-75.

${ }^{28}$ International Agency for Research on Cancer. Monographs on the evaluation of carcinogenic risk of chemicals to man. Vol 2. Some inorganic and organometallic compounds. Lyon: IARC, 1973:100-25.

${ }^{29}$ International Agency for Research on Cancer. Monographs on the evaluation of carcinogenic risk of chemicals to humans. Vol 23. Some metals and metallic compounds. Lyon: IARC, 
1980:205-323.

${ }^{30}$ Maltoni C. Occupational carcinogenesis. Excerpta Medica International Congress Series 1974;322:19-26.

${ }^{31}$ Maltoni C. Predictive value of carcinogenesis bioassays. Ann NY Acad Sci 1976;271:431-43.

${ }^{32}$ Furst A, Schlauder M, Sasmore DP. Tumorigenic activity of lead chromate. Cancer Res 1976;36:1779-83.

${ }^{33}$ Hueper WC, Payne WW. Experimental studies in metal carcinogenesis, chromium, nickel, iron, arsenic. Arch Environ Health 1962;5:445-62.

${ }^{34}$ Pettrilli FL, De Flora S. Toxicity and mutagenicity of hexavalent chromium on Salmonella typhimurium. Appl Environ Microbiol 1977;33:805-9.

${ }^{35}$ Pettrilli FL, De Flora S. Mutagenicity of chromium compounds. In: Proceedings of the chromate symposium 80. Focus of a standard. Rockville, Maryland: Industrial Health Foundation Inc, Penn, 1981.
${ }^{36}$ Bianchi V, Celotti G, Lanfranchi F, et al. Genetic effects of chromium compounds. 1. Mutat Res 1983;117:279-300.

${ }^{37}$ Sanderson CJ. The uptake and retention of chromium by cells. Transplantation 1976;21:526-9.

${ }^{38}$ Mertz W. Chromium occurrence and function in biological systems. Physiol Rev 1969;49:163-239.

${ }^{39}$ Polak L, Turk JL, Froy JR. Studies on contact hypersensitivity to chromium compounds. Prog Allergy 1973;17:145-226.

${ }^{40}$ Tsapakos MJ, Wetterhahn KE. The interaction of chromium with nucleic acids. Chemico-Biological Interactions 1983;46:265-77.

${ }^{41}$ Alderson MR, Rattan NS, Bidstrup PL. Health of workmen in the chromate-producing industry in Britain. $\mathrm{Br} J$ Ind Med 1981;38:117-24.

${ }^{42}$ Davies JM. Lung cancer mortality in workers in chromate pigment manufacture: an epidemiological survey. Journal of the Oil and Colour Chemists' Association 1979;62:157-63.

\section{Vancouver style}

All manuscripts submitted to the $B r J$ Ind Med should conform to the uniform requirements for manuscripts submitted to biomedical journals (known as the Vancouver style).

The $\mathrm{Br} J$ Ind Med, together with many other international biomedical journals, has agreed to accept articles prepared in accordance with the Vancouver style. The style (described in full in $\mathrm{Br}$ Med J, 24 February 1979, p 532) is intended to standardise requirements for authors.

References should be numbered consecutively in the order in which they are first mentioned in the text by Arabic numerals above the line on each occasion the reference is cited (Manson' confirmed other reports ${ }^{2-5} \ldots$..). In future references to papers submitted to the $\mathrm{Br} J$ Ind Med should include: the names of all authors if there are six or less or, if there are more, the first three followed by et al; the title of journal articles or book chapters; the titles of journals abbreviated according to the style of Index Medicus; and the first and final page numbers of the article or chapter.

Examples of common forms of references are:

' International Steering Committee of Medical Editors. Uniform requirements for manuscripts submitted to biomedical journals. Br Med J 1979; 1:532-5.

2 Soter NA, Wasserman SI, Austen KF. Cold urticaria: release into the circulation of histamine and eosinophil chemotactic factor of anaphylaxis during cold challenge. $N$ Engl $J$ Med 1976;294:687-90.

' Weinstein L, Swartz MN. Pathogenic properties of invading micro-organisms. In: Sodeman WA Jr. Sodeman WA. eds. Pathologic physiology: mechanisms of disease. Philadelphia: W B Saunders, 1974:457-72. 